\title{
12. A Institucionalização do Ensino Médico
}

\author{
Joffre Marcondes de Rezende
}

\section{SciELO Books / SciELO Livros / SciELO Libros}

REZENDE, J. M. A Institucionalização do Ensino Médico. In: À sombra do plátano: crônicas de história da medicina [online]. São Paulo: Editora Unifesp, 2009, pp. 121-129. História da Medicina series, vol. 2. ISBN 978-85-61673-63-5. https://doi.org/10.7476/9788561673635.0013.

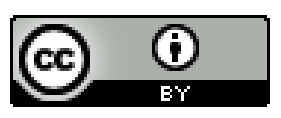

All the contents of this work, except where otherwise noted, is licensed under a Creative Commons Attribution 4.0 International license.

Todo o conteúdo deste trabalho, exceto quando houver ressalva, é publicado sob a licença Creative Commons Atribição 4.0.

Todo el contenido de esta obra, excepto donde se indique lo contrario, está bajo licencia de la licencia Creative Commons Reconocimento 4.0. 


\section{A Institucionalização do Ensino Médico}

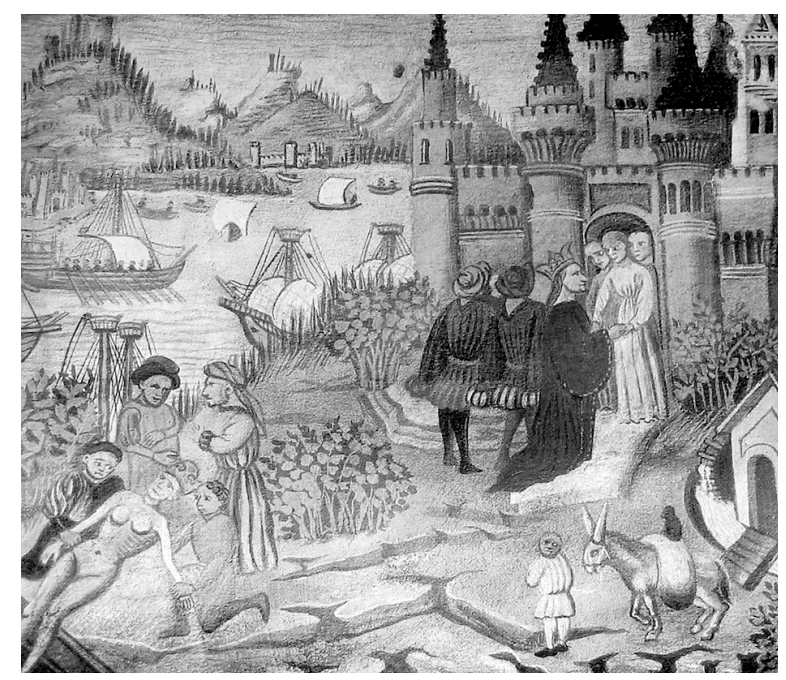

Escola de Salerno, miniatura no Canon de Avicena.

\section{A Escola de Salerno e as Primeiras Universidades Europeias}

$\mathrm{O}$ ensino médico no Ocidente só foi institucionalizado na Idade Média. Após a invasão do Império Romano pelos bárbaros no século v, a medicina na Europa, como toda a cultura clássica greco-romana, se abrigou nos mosteiros. Diversas ordens religiosas preservaram grande parte dos manuscritos sobre a medicina e tomaram a seu cargo o cuidado aos enfermos como um preceito cristão. Pequenos hospitais e albergues eram encontrados junto aos mosteiros, onde os doentes eram atendidos.

Um dos mosteiros que mais se destacaram nessa atividade foi o de Monte Casino, na Itália, fundado por São Bento em 529, de onde surgiu a ordem dos beneditinos.

Além dos clérigos, havia, paralelamente, médicos leigos menos preparados, espalhados por toda a Europa. Esta situação iria perdurar por cerca de três séculos, até que surgisse a Escola de Salerno. Salerno, uma pequena cidade litorânea situada ao sul de Nápoles, na Itália, era procurada pelos 
enfermos, em virtude do seu clima ameno e saudável. Este fato atraiu muitos médicos para a cidade.

Em 820, os beneditinos fundaram um hospital em Salerno e passaram a exercer a medicina ao lado dos médicos leigos. Os monges tinham conhecimento dos autores clássicos, como Hipócrates e Galeno, enquanto os leigos eram médicos práticos de pouca cultura.

Há referências ao ensino da medicina em Salerno já no século Ix, porém a sua institucionalização só se deu em 1075 , graças a Constantino, o Africano. A partir daí a escola estabeleceu um currículo regular e passou a receber auxílio financeiro dos governantes.

A escola de Salerno alcançou fama mundial, para ela acorrendo estudantes de todas as nações. $\mathrm{O}$ ensino era essencialmente prático e permitiu-se o ingresso de estudantes do sexo feminino. A influência da Igreja na escola de Salerno declinou progressivamente até desaparecer por completo.

A escola de Salerno contribuiu principalmente para o desenvolvimento da medicina como profissão. O curso médico exigia estudos preparatórios e mais cinco anos, o último dos quais equivalente ao atual internato. Para os alunos aprovados ao final do curso fornecia-se uma licença para exercer a medicina.

O prestígio da escola de Salerno decaiu após a criação da escola de Nápoles e, ao ser extinta em I 8I I, por um decreto de Napoleão, já deixara de existir há tempos. Sua contribuição científica ao progresso da medicina foi pequeno. Os seus ensinamentos acham-se consubstanciados em um poema intitulado "Flos Medicinae" ou "Regimen Sanitatis Salernitanum", do qual existem cerca de trezentas edições em várias línguas. Este poema contém uma série de regras para conservar a saúde. Os livros escritos pelos professores de Salerno eram principalmente textos didáticos, alguns com feição de verdadeiras apostilas. Muitos deles não trazem sequer o nome do autor. Outros são traduções de textos árabes feitas por Constantino, o Africano, que se tornou conhecido como Magister orientis et occidentis. O ensino da anatomia era feito em porcos.

Dentre os mais célebres médicos de Salerno citam-se: Benevenuto Grasso, autor de Practica oculorum, um manual de doenças dos olhos que foi tido como texto clássico de oftalmologia durante quinhentos anos; Gilles de Corbeil, que escreveu todas as suas obras em versos. Um dos poemas, "Carmina urinarum", é dedicado à uroscopia, um dos métodos diagnósti- 
cos mais utilizados na época. Descreveu vinte cores diferentes de urina; e Rogerius Frugardi, cuja obra, conhecida por Cyrurgia Rogerii, foi posteriormente adotada em outras escolas. Nela existe a recomendação do uso de algas marinhas no tratamento do bócio (as algas contêm iodo) (Bullough, I966, pp. 49-52; Castiglioni, I947, pp. 350-377).

Trecho do poema "Flos Medicinae" ("Flor da Medicina")

Se quereis conservar-vos incólume e sadio,

evitai os cuidados ansiosos, guardai-vos da ira.

Poupai o vinho, sede parco na ceia; não julgueis inútil

o levantar-vos após a refeição e fugi da sesta ao meio dia

Reter as urinas ou a defecação seja-vos interdito

Guardando estes conselhos, longo tempo heis de viver

Caso vos faltem médicos, três coisas suprirão suas vezes:

hilaridade, repouso e dieta moderada.

\section{As Universidades Medievais}

O legado imperecível da Idade Média à civilização ocidental consistiu no estabelecimento das universidades.

A palavra latina universitas foi inicialmente empregada a partir do século XII para designar uma corporação de professores e alunos. Subdividiu-se depois em dois ramos: a de leis e a de artes e medicina. O local de ensino era chamado de studium.

Somente a partir do século XIV, universitas passou a designar também a própria instituição, tal como hoje a entendemos.

\section{Bolonha}

Uma das mais antigas universidades europeias, iniciou-se como uma escola de leis, transformando-se em universidade em I I 58 . Era uma universidade de estudantes, ao contrário das demais.

Os estudantes pagavam taxas de manutenção, escolhiam seus professores e elegiam o reitor, cuja importância na cidade era maior do que a da autori- 
dade eclesiástica. Os professores eram pagos pelas lições que ministravam e aqueles mais procurados pelos alunos ganhavam mais que os outros. Para o curso médico havia exame de qualificação e concedia-se aos professores total autoridade para seleção dos candidatos.

No século XIII a cidade passou a contribuir para a contratação de professores. A cidade orgulhava-se de sua universidade, que recebia estudantes de outras nações e chegou a ter quinze mil alunos no ano de I 320 .

Havia pena de morte para os professores que fossem ensinar em outra cidade sem permissão.

$\mathrm{Na}$ Universidade de Bolonha destacaram-se: Taddeo Alderotte (I 223-I303), um clínico famoso na época e escreveu Concilia, uma coletânea de histórias clínicas; Theodorico de Lucca ( I 205-I289), professor de cirurgia, que revolucionou o tratamento das feridas sugerindo sutura imediata para evitar a formação de pus, na época considerado inevitável; Guglielmo de Saliceto, médico e cirurgião, autor de dois livros: In Scientia Medicinale e Cyrurgia, que praticava a sutura de nervos e foi o primeiro a fazer dissecção na universidade, contrariando as recomendações da Igreja; e Remondino de Luzzi (I270-I326), também conhecido por Mondino, autor de um tratado de anatomia no qual sistematizou a dissecção. Somente em I405 a dissecção foi oficialmente autorizada na universidade (Bullough, op. cit., pp. 60-68; Major, 1954, pp. 290-302).

\section{Montpellier}

Cidade situada ao sul da França, próxima à Espanha, cedo destacou-se como centro de ensino médico na Idade Média. Em i i 8 I, o soberano Guilherme VIII abriu as escolas lá existentes a professores de todos os credos e nacionalidades. Com isso, judeus e cristãos, perseguidos na Espanha, emigraram para Montpellier.

A própria população da cidade era formada de imigrantes de várias nacionalidades. Havia três faculdades funcionando isoladamente: leis, artes e medicina, as quais só foram reunidas em universidade no ano de I 289.

A cirurgia não integrava o currículo e deveria ser aprendida à parte. $\mathrm{O}$ curso compreendia três etapas: a de bacharel (três anos e seis meses), a de licenciado (mais seis meses de prática e exames finais) e a de master, após 
um exame rigoroso, que durava vários dias. O grau de master era conferido em uma cerimônia solene na Igreja de São Firmino, em presença da comunidade universitária e de convidados.

Foram nomes destacados na Faculdade de Montpellier: Arnold de Villanova (I235-I3 II), educado pelos frades dominicanos, estudou teologia e era homem de grande cultura. Conhecia grego, latim, árabe, falava fluentemente italiano e catalão, ensinava em provençal, que era a língua falada no sul da França. Foi médico de papas e reis. Era astrólogo e alquimista e um experimentador infatigável. Considerado por muitos como mágico e feiticeiro, foi acusado de heresia, tendo sido salvo pelo papa Bonifácio viII, que era seu cliente. Da sua vasta obra são mais conhecidos os livros Parábolas e o seu Breviário, uma espécie de manual sobre todas as doenças. Traduziu diversas obras de Avicena do árabe para o latim.

Ramon Lull (I232-I3 I6) era um frade dominicano que aos 63 anos passou para a ordem dos franciscanos. Viajou muito e estudou árabe com a finalidade de converter muçulmanos ao cristianismo. Escreveu cerca de I 50 livros sobre teologia, lógica, cavalaria, educação física, alquimia e medicina. A ele se atribui a descoberta do éter sulfúrico.

Guy de Chauliac (I300-1368), o maior cirurgião da Idade Média. Escreveu Cyrurgia magna, livro que teve dezesseis edições em latim, 43 em francês e muitas outras em alemão, holandês, inglês e espanhol (Bullough, op. cit., pp. 52-60; Major, op. cit., pp. 302-3 I2).

\section{Paris}

Ao contrário de Bolonha, a Universidade de Paris era uma corporação fechada de professores, sem a menor participação dos estudantes na sua administração. Atribui-se a Carlos Magno a sua fundação, porém não existe nenhum documento que o comprove.

A Universidade de Paris ficou sob o domínio da Igreja desde I 2 I 5. Exigia-se o celibato, tanto dos professores como dos alunos. Em I395 um aluno que havia se casado não pôde receber grau de médico. Em I 443 o reitor perdeu seu cargo pelo duplo crime de desposar uma viúva. Essa exigência foi abolida em I452. A Faculdade de Medicina permaneceu sob o controle da Igreja até I 595. 
A Universidade de Paris se destacou pelos cursos de teologia e filosofia, o que valeu a Paris a denominação de cidade-luz. O ensino médico, entretanto, nunca alcançou a reputação das escolas de Salerno, Bolonha e Montpellier. $\mathrm{O}$ médico que desejasse pertencer à universidade deveria abandonar a cirurgia, sob juramento. A Universidade de Paris aprofundou, assim, a separação existente entre médicos e cirurgiões, os quais organizaram-se em outra corporação: a Confraria de São Cosme.

Para tornar-se professor da universidade exigia-se uma série de condições, dentre as quais a apresentação e defesa de uma tese, inovação que foi copiada por outras universidades e sobrevive até os nossos dias.

O curso médico a partir de 1270 era dado em seis anos, dividido em duas etapas. $\mathrm{O}$ aluno deveria jurar antes de cada exame que não prejudicaria o seu professor em caso de reprovação.

Destacaram-se na Universidade de Paris: Albertus Magnus (I 206-?), canonizado como santo pelo papa Gregório XV em I 622, era teólogo, filósofo, astrônomo, físico, químico, geógrafo, botânico e zoólogo. Publicou numerosos livros, destacando-se por seus conhecimentos sobre plantas medicinais. Suas lições eram tão concorridas e disputadas que foi necessário construir um anfiteatro ao ar livre para suas aulas. Foram seus discípulos Tomás de Aquino, posteriormente canonizado pela Igreja, Roger Bacon e Petrus Hispanus.

Petrus Hispanus (I210-I 277), de origem portuguesa, foi para Paris estudar teologia, lógica e medicina. Escreveu Thesaurus pauperum (Tesouro dos Pobres), uma espécie de Vade-mecum que cuidava de todas as doenças, "da cabeça aos pés". Foi médico do papa Gregório x, que o nomeou cardeal. Com a morte do papa, foi eleito papa, com o nome de João xxi. Foi o primeiro e único médico a ocupar o papado. Faleceu um ano depois de ter-se tornado papa.

Lanfranchi (?-I306) ensinou cirurgia na Faculdade de Medicina, antes da exclusão da cirurgia. Combateu a separação entre médicos e cirurgiões e defendeu a ideia de que o cirurgião devia ser médico e que o médico devia ter conhecimentos de cirurgia. Escreveu um tratado sob o título de Cyrurgia magna (Bullough, op. cit., pp. 68-72; Major, op. cit., pp. 3 I 2-322). 


\section{Oxford e Cambridge}

Foram as primeiras universidades inglesas. A Universidade de Oxford foi uma cópia da de Paris e iniciou-se com estudantes e clérigos ingleses emigrados da França por razões políticas. Foi oficialmente reconhecida por uma Carta Real de I2 I7. Em I 229, em consequência de um tumulto, parte dos estudantes transferiu-se para Cambridge, onde foi criada uma nova universidade.

O ensino médico em Oxford e Cambridge, tal como em Paris, continuou a ser dado em latim e era essencialmente teórico. A parte prática consistia na leitura pelo professor de textos clássicos, que eram a seguir discutidos pelos alunos. Daí o nome de lente (aquele que lê) dado ao professor (em inglês reader, termo ainda hoje usado na Inglaterra).

Destacaram-se nas duas universidades inglesas: Bartholomeus Anglicus escreveu por volta de $\mathrm{I} 250$ uma enciclopédia intitulada De proprietatibus rerum (Das Propriedades das Coisas), que se tornou obra de consulta obrigatória na Idade Média. São conhecidas dessa obra dezesseis edições em latim, oito em francês, três em inglês, duas em espanhol e uma em holandês. A medicina ocupa setenta capítulos e retrata os conhecimentos da época. Nela se lê que o baço é a fonte da alegria, a vesícula da cólera, o fígado do amor e o coração da sabedoria. "As veias originam-se do fígado, as artérias do coração e os nervos do cérebro". Na edição francesa de I482 aparece pela primeira vez a ilustração de uma dissecção anatômica em livro impresso.

Roger Bacon (I 2 I4-I 292) - não deve ser confundido com Francis Bacon, do século XVI - era frade franciscano, de grande cultura, tendo escrito sobre teologia, matemática, óptica e geografia. Foi um profeta e visionário. Previu a existência de outro continente, assim como de barcos sem remos, armas de fogo e máquinas voadoras. Contribuiu para o desenvolvimento das lentes de aumento, "que poderiam servir para leitura". Pertence a ele a frase de que "a razão nada prova, sendo necessária a experiência". Sua obra foi condenada pela Igreja e ele passou os últimos quinze anos de sua vida na prisão.

John of Gaddesten, autor do livro Rosa Anglica ( 1280 ). Sua pouca modéstia se espelha na apresentação do livro: "Assim como a rosa se sobrepõe a todas as flores, assim este livro se sobrepõe a todos os tratados de medicina”. 
Seu livro foi considerado por alguns críticos como destituído de valor e Guy de Chauliac se referiu a ele como uma rosa sem perfume. Uma das poucas coisas que escreveu e que permanece útil é a restrição de sal aos pacientes edematosos (Major, op. cit., pp. 322-326).

\section{Pádua}

A Universidade de Pádua, a segunda maior universidade a ser criada na Itália, foi fundada por professores e alunos da Universidade de Bolonha, que estavam descontentes com o regime autoritário e opressivo a que estavam submetidos. A Universidade de Pádua foi oficialmente reconhecida em I 222 e teve rápido progresso, ultrapassando a de Bolonha, em razão de sua conduta liberal, acolhendo professores e alunos independentemente de sua origem, nacionalidade, raça ou credo, sem a interferência da Igreja. Tal como em Bolonha, os estudantes elegiam os professores e o reitor.

Dentre os primeiros professores de medicina destacaram-se: Bruno da Longobardo, autor de um tratado, Cyrurgia magna, uma compilação de autores gregos e árabes, acrescida de suas próprias observações. Distinguia o sangramento venoso do arterial, fazia ligadura de vasos com fio de seda e procurava obter a cicatrização das feridas por primeira intenção.

Pedro de Abano, graduado em Paris em filosofia, matemática e medicina, gozava de grande reputação como médico e como professor. Escreveu Conciliator, no qual procurava conciliar as divergências da medicina árabe com a medicina grega, e De Venenis, que trata dos venenos, dos sintomas por eles produzidos e dos respectivos antídotos. Por seus conhecimentos de astrologia e alquimia, foi acusado de heresia pela Inquisição. Como falecera antes da condenação e seu corpo não foi encontrado, queimaram sua efígie em praça pública.

Gentile da Foligno foi um dos mais famosos professores. Era médico do conde Ubertino de Carrara. Realizava dissecções públicas e em uma de suas autópsias registrou o achado de um cálculo na vesícula biliar. Escreveu vários trabalhos, sendo o mais importante Concilia contra pestilentia.

Com o passar do tempo, a Universidade de Pádua tornou-se o maior centro do saber da Europa, atraindo estudantes de todas as nações. Teve a glória de ter Galileu como um de seus professores durante dezoito anos. A área 
médica contou com os maiores nomes de sua história, seja como professores, seja como alunos, tais como Vesalius, Fallopio, Colombo, Acquapendente, Morgagni, Sanctorio, Fracastoro, Harvey e muitos outros (Major, op. cit., pp. 327-333; Rossetti, I983, pp. 5-59).

Após a Universidade de Pádua, outras foram fundadas na Itália, França, Espanha e Portugal, totalizando dezesseis universidades na Europa ao final do século XIII. Fora do continente europeu, contam-se entre as universidades mais antigas do mundo as de Marrocos, Cairo e Bagdá, fundadas, respectivamente, nos anos de 859, 988 e I233.

\section{Referências Bibliográficas}

Bullough, V. L. The Development of Medicine as a Profession. Basel, S. Karger, I966. Castiglioni, A. História da Medicina. São Paulo, Cia. Editora Nacional, 1947.

Major, R. H. A History of Medicine. Oxford, Brackwell Scientific Publications, I954. Rossetti, L. The University of Padua. Trieste, Edizione Lint, I983. 
